\title{
Reform and Practice of Track and Field General Education Based on Inquiry
}

\author{
Lu Changchun \\ School of physical education, Leshan Normal University, Leshan, Sichuan 614000, China \\ luchangchun@126.com
}

Keywords: inquiry track and field general operation mode.

\begin{abstract}
This paper makes an empirical study of the inquiry teaching method in the general course of track and field for PE majors in colleges and universities by using the methods of literature and teaching practice. This paper probes into the three parts of pre-class preparation, running, jumping, project starting, basic and ending, puts forward the inquiry teaching mode and method of each part, and the requirements of teachers, and constructs the amount of "lessons", "certificates" and "competitions" which are compatible with the inquiry teaching method, "superimposed" track and field general course evaluation.
\end{abstract}

\section{Introduction}

According to the notification of the Ministry of Education and other five departments on the issue of the Action Plan for Teacher Education Revitalization (2018-2022), one of the objectives of the circular is to innovate the mode of teacher education, train future outstanding teachers as the goal, and promote the main measures of teaching reform characterized by autonomy, cooperation and inquiry [] [1]. As one of the backbone courses of physical education in Colleges and universities, the reform of track and field course should also keep pace with the times. Most of the contents of track and field items are in the main position in the physical education and health course of basic education. Therefore, it is necessary to study the effect of inquiry teaching method in the teaching of track and field course for the cultivation of future sports knowledge.

The innovative and creative abilities and the desire to seek knowledge of the imparters have obviously promoted the development of the local colleges and universities to make the teacher's major a strong strategic goal to lay a solid foundation.

\section{Explore the application connotation of track and field general course teaching}

The teaching of inquiry-based general course of track and field is based on the basic professional development requirements of physical education and health course for physical education teachers in basic education at this stage, combined with the natural law of the teaching of general course of track and field, under the guidance and assistance of teachers, students understand and learn through independent study, independent research, active discussion, and final summary. To master a basic teaching principle of track and field project and a teaching mode of motor skills and skills. At the present stage, local colleges and universities track and field course less hours, more content; simple and boring teaching method is a common phenomenon. How to solve the problem within a limited time, use effective teaching methods to change the status quo, promote the improvement of teaching quality, is the urgent task of higher education workers. According to the situation of students'origin, local colleges and universities analyze that most of their future service objects are in the scope of the province. The application-oriented people trained can serve the local areas. How to effectively link up the students majoring in Physical Education in local colleges and universities to adapt to the work of physical education in primary and secondary schools as soon as possible after graduation is the major of physical education in local colleges and universities. Problems that need to be solved in teaching. The teaching process of inquiry-based teaching method is completed by four stages of 
putting forward hypothesis (question) - practical screening problem - exploring and combing evaluating promotion. Its advantage lies in changing the traditional "teacher-centered" pressure-filled teaching method into "student-centered" and active exploration. "Active and flexible" cooperative learning mode. Attaching importance to the student's principal position [2], the teacher is the guide, assisting the students to complete the teaching task of the track and field course together.

\section{Explore the operation mode of track and field general course teaching}

\subsection{Explore the preparation before class}

Is the preparation for a teacher well prepared and adequate before class? It is the key to decide whether the teaching goal can be achieved after the implementation of teaching. Inquiry is the meaning of "in-depth discussion and repeated research" [3]. According to the Trinity analysis of the teaching syllabus of the track and field course, the common problems in daily teaching and the requirements of the basic physical education and health course to the physical education teachers, the teachers arrange the seamless joint among several small items in the three big events of running, jumping and throwing in a school year. According to the similarity of track and field events and the natural laws of teaching, such as: the first semester is mainly to explore the preparatory running and throwing events, the second semester to explore preparatory jumping events and track and field basic teaching methods. Interest is the best teacher. Inquiry teaching should be based on students' interests, [4]. Explore how to effectively link up the small projects, analyze the learning situation, analyze the teaching materials, put forward the hypothesis according to the actual situation of the last lesson design the topic of the project which can arouse students'active attention and discussion in the next lesson, so as to successfully explore and complete the teaching task in the next lesson while receiving good results. For example, before the teaching of sprint technical movements, we can ask questions such as what is the world record for men (women) 100 meters to arouse students'interest and thinking.

\subsection{Part of warming up activities in inquiry class}

The preparatory activities of traditional track and field courses are composed of jogging, bare-handed gymnastics, marching activities and special preparatory activities, lasting about 30 minutes. This is a constant pattern of preparatory activities for many years. According to the contents and tasks of this lesson, we can adopt the organizational methods of decentralization, centralization, grouping and so on. Students can design their own unique content and methods of preparation activities according to their own special abilities in combination with the learning tasks of this lesson, and do well in the way of self-determination or unity and cooperation within the prescribed time. For example, taking a group of about 10 people as a unit, using games, gymnastics, special preparatory activities, flexible exercises and other flexible collocation organization, not only can achieve the desired teaching objectives, but also can promote students'active participation, positive thinking, fully reflects the student-centered, teacher-assisted interactive and cooperative learning atmosphere, to achieve students from passive to active. Active participation in learning habits. At the end of each preparatory activity, a summary group discussion, a grade assessment, recorded in the final comprehensive score, while throwing out the theme of the next class, leaving students to explore the preparation part of the time and topics for the next class to lay the foundation.

\subsection{The basic part of inquiry class}

The purpose of the preparatory activities is to warm up, and the role of the basic part is the key stage for students to master the normal skills. The traditional teaching mode of track and field course is basically composed of teacher's explanation - Demonstration - Practice - error correction consolidation and improvement or review - error correction - consolidation and promotion. Every strategy of physical education should first consider how students learn [5]. After the teacher deeply analyzes the students'psychological status and thinking mode at this stage, designs comfortable learning space practice experience, the teacher guides the introduction of a certain technical 
movement in the track and field course several technical movement postures, according to the content of this lesson and the questions raised in the last lesson (oneself has found the answer) Students can also develop new exercises to experience. After the students have undergone empirical inquiry, the students'teachers discuss and inquire into the answers together, and then adopt feasible exercises after the empirical inquiry. Way to achieve the final learning results, complete the teaching task. For example, in the teaching process of short-throw and long-throw in throwing events, the first step is to use the hypothetical questions raised in the last lesson, and the results have been analyzed after class. In this lesson, the students are suggested to use shoulder-up throw, shoulder-up throw, shoulder-Down throw, left-hand throw, right-hand throw and other ways to practice. The second step is to focus on students, teachers and students together to explore, think and communicate, what is the most far most of the best way to practice, and then we practice together to experience one or more of the basic practice that everyone agrees with, to find the best 1-2 practice. The third step is that teachers put forward suggestions for students to practice, experience the practice, and finally teachers and students together to explore the way to study long-distance, explain its technical action essentials, students practice to achieve teaching objectives. In the process of inquiry teaching, students explore experience and practice more time, and have a definite aim. For individual students, they can adopt a learning style similar to his physical structure, and change "want me to explore" to "want to explore" [6]. To guide students to observe and understand practical cases, discover problems or key points, explore and discuss solutions to problems, analyze anatomical problems, collect data, actively verify and screen solutions, and finally find the best solutions to the problems. The best way is to create new ideas, new ways and new ways of action.

Physical education teachers teach physical education knowledge, for physical education has a unique attribute, most of the time is to teach knowledge outdoors, intuitive demonstration is the most direct and effective teaching behavior, beautiful demonstration action plus a profound understanding of the practical operation of the explanation is the most profound. In the basic teaching method of track and field events, explore its teaching principles, teaching methods, cultivate students'practical operation ability, using the "one-to-one" and "one-to-one" teaching process. For example, in the teaching process of the long jump flying step, the student who adopts excellent or high-level technical movements acts as an assistant teacher, and one or two to five students with poor motor skills to explore and discuss, through their own profound understanding and understanding, to share the learning process with other students, to help motor skills. Poor students together to improve the long jump step. The process to promote the students'ability to demonstrate movement, language and communication skills, after a period of practice, the poor part of the technical movement of the students in front of all the students in the class to carry out a long jump demonstration race, after all the assistant teachers to further improve the evaluation, in order to promote students To be positive and enterprising, cultivate their core literacy and ability to enhance, in order to achieve the teaching purpose of learning to apply. Students and assistant teachers who have made great progress are recorded in the evaluation of the learning process to promote the organic integration of "learning (learning), teaching (teaching assistant), evaluation (evaluation)" and lay the foundation for training truly applied talents.

\subsection{The end of inquiry class}

Relaxation exercise is an indispensable part of physical education. It not only helps the active recovery of physical skills, but also a means of physical and mental recovery. The traditional track and field relaxation exercise is 3-5 parts of jogging, relaxing or relaxing gymnastics. Using inquiry teaching method, students relax themselves and cooperate with each other to relax in 2-3 groups.

The progress of learning needs continuous reflection and summary. In the part of curriculum summary, the traditional teaching mode of one-man summary is changed into the mode of combining students'self-summary with teachers' comments. The students can evaluate and summarize directly according to their own or students'learning activities. At this time, teachers as organizers, listeners and participants, guide students to communicate and summarize in an objective and fair manner. Students treat correctly the conclusions and suggestions given by other students with an inclusive 
attitude, and gradually form a harmonious and corrective communication process.

\section{Explore the teaching requirements of track and field general courses}

In order to improve the rational use of inquiry teaching methods in professional academic disciplines, first of all, it is necessary to establish a good teacher-student relationship platform. Teachers and students are actors on this platform, everyone is equal, everyone participates, and teachers and students participate in the whole process. Teachers take the initiative to discuss and exchange opinions with students, share their own learning and teaching experience in the process of inquiry teaching, gradually understand students'real ideas, and share the fruits of inquiry learning together, especially the need to have a love to respect, care for and help poor students, so that this part of the students in inquiry learning. Cheng Zhong appreciated the equal and mutual respect between students and teachers, thus promoting the active participation of this part of students, seriously take each lesson, fully mobilize the initiative of each student, to achieve the "happy learning" of students with the "happy teaching" of teachers[7].

Secondly, teachers should stand in the perspective of students to consider what kind of circumstances I would be interested to participate in the teaching activities of this lesson, especially the timing of the hypothesis problem, in the appropriate occasions to put forward problems related to the importance and difficulty of this lesson. For example, what is the world record of the long jump in the air movement technology teaching stage of long jump? Who created it? What aerial posture do you use? What is the posture of air movements that Chinese athletes basically adopt at this stage? After the students'on-the-spot answers, the teachers make full use of the means of network education to verify the aerial technical movements of the elite long jumpers at home and abroad, so that the students have a profound experience and intuitive impression. In the process of inquiry, according to the students'thinking mode and cognitive law, the environment of active learning is designed to stimulate learning interest and promote self-inquiry learning.

Secondly, teachers should stand in the perspective of students to consider what kind of circumstances I would be interested to participate in the teaching activities of this lesson, especially the timing of the hypothesis problem, in the appropriate occasions to put forward problems related to the importance and difficulty of this lesson. For example, what is the world record of the long jump in the air movement technology teaching stage of long jump? Who created it? What aerial posture do you use? What is the posture of air movements that Chinese athletes basically adopt at this stage? After the students'on-the-spot answers, the teachers make full use of the means of network education to verify the aerial technical movements of the elite long jumpers at home and abroad, so that the students have a profound experience and intuitive impression. In the process of inquiry, according to the students'thinking mode and cognitive law, the environment of active learning is designed to stimulate learning interest and promote self-inquiry learning.

\section{Explore the requirements of teachers in track and field teaching}

Using inquiry teaching mode requires teachers to establish equal relationship between teachers and students in the classroom. Teachers can not help but integrate themselves into an equal and harmonious team learning platform. Teachers are organizers, advocates and participants of inquiry teaching activities [8] when applying inquiry teaching method in the general course of track and field. The main task of inquiry is to promote students'innovation, advocate unity and cooperation and improve students' practical expression ability. Teachers and students explore, analyze and exchange, and develop their final learning process together. Teachers first of all have advanced educational and teaching concepts with the times; track and field technology and teaching subject knowledge frontier. Secondly, the relevant knowledge requirements of track and field in physical education and health courses in basic education. Thirdly, it can quickly absorb the new knowledge of track and field technical teaching, and has the ability to deal with problems in the process of discussing with students in a timely manner. Finally, teachers are required to have noble morality, skilled track and field 
teaching skills, active innovation and strong track and field scientific research ability, integrating professional technology, intellectual education, moral education in one.

\section{Explore the evaluation system of track and field courses}

\subsection{Build a scientific and reasonable evaluation method.}

The traditional track and field course evaluation system is basically composed of attendance, technical evaluation and standards. Quantification is better than non-quantification, the proportion of quantitative evaluation is larger, the proportion of process evaluation is smaller, the consequence is that it can not fully and reasonably reflect the degree of effort and progress in the learning process, for students with poor foundation, can not objectively evaluate the learning process of a school year, is not conducive to fully mobilizing students'enthusiasm for learning. . In the teaching process, the implementation of inquiry teaching method requires students to participate in the whole process from pre-class, in class and after-class. In the whole teaching process, all students actively explore the experience, in the realization of their knowledge goals, emotional goals in the process of devoting sweat and energy. The implementation of the "itemized quantitative superposition" Diversified Assessment system, focusing on increasing the weight of process evaluation, weakening the quantitative evaluation, fully reflects the concept of everyone's participation, full participation, equality of all teaching.

\subsection{Content analysis}

The scientific and reasonable evaluation content can not only reflect the comprehensive coverage of knowledge points in the teaching process of track and field course, but also reflect the students'efforts in the learning process, so that the students' learning process can be reflected. The evaluation content of the "itemized quantitative superposition" examination system can solve the above mentioned problems perfectly. Practice has proved that the combination of "lessons (courses), certificates (certificates of honor, referees, skills related to physical education), competitions (lectures related to teachers'skills, technical exhibition, Blackboard Design and other competitions) The evaluation concept proves that the "itemized quantitative superposition" assessment system is scientific and forward-looking, and its specific contents are as follows:

Table 1 the composition of evaluation contents of exploratory track and field courses

\begin{tabular}{lll}
\hline & \multicolumn{3}{c}{ Composition and proportion of achievements } & training project $30 \%$ & practical skills $20 \%$ \\
\cline { 2 - 3 } $\begin{array}{l}\text { Semester } \\
\text { sports participation } 10 \%\end{array}$ & & \\
\hline $\begin{array}{l}\text { First semester } \\
\text { evaluation }\end{array}$ & $2-4$ items (skills, refereeing knowledge, lecture contests, etc.) & $2-3$ items of process \\
$\begin{array}{l}\text { Second term } \\
\text { assessment }\end{array}$ & $2-4$ items (technology, referee knowledge, lecture contest, etc.) & $2-3$ items of process \\
theory papers attendance and classroom participation in the second semester
\end{tabular}

\section{Conclusion}

Inquiry-based general track and field teaching, habitual teachers give answers, students learn to break the habit of teaching behavior, students'free space for autonomous learning has been promoted, in the process of track and field teaching students play the main situation incisively and vividly, learning enthusiasm in the process of learning to fully mobilize, interactive cooperation, people The new relationship between teachers and students has been affirmed and developed. Inquiry-based track and field teaching is highly integrated with the concept of "lessons, certificates, competitions" education, combined with the seamless docking of the "itemized quantitative superposition" diversified evaluation system, the overall teaching quality and effect of track and field courses have been clearly mentioned, while improving the students'teachers' professional skills and core 
competence, students are in the field at the same time. Knowledge of technical movements and skills has also been greatly developed.

\section{Acknowledgements}

Fund project: Leshan Normal University 2015 school-level education and teaching reform research general project - based on inquiry track and field teaching reform and practice of research results.

(Topic number: 34$)$.

\section{References}

[1] The Ministry of Education and other five departments. The Ministry of Education and other five departments on the issue of the Action Plan for the Revitalization of Teacher Education (2018-2022)

Notice.[EB/OL]. 2018.03.22. http://www.moe.gov.cn/srcsite.

[2] Wu Satellite. Research on the Reform of Track and Field Course Teaching of Physical Education Major in Colleges and Universities in the New Period [J].Journal of Shanxi University of Finance and Economics, 2015, 4:158-159.

[3] Zhang Yin et al. Time of Return, Problem of Return, Subject of Return - On the Essence, Characteristics and Implementation Model of Inquiry Teaching [J].Jiangsu Higher Education, No. 4, 2013: 67.

[4] and Guanghui. Analysis of college sports inquiry teaching [J]. Adult education in China, 2010 eleventh issue: $182-183$.

[5] gold inscription and so on. Inquiry track and field teaching mode [J]. Sports journal, 2003, 3:88.

[6] Wu Changqing et al. The organizational strategy of inquiry teaching in physical education curriculum [J]. Journal of Yangtze River Engineering Vocational and Technical College, 2014, 3:77.

[7] Qufei. On the Cultivation of College Students'Track and Field Teaching Ability and the Countermeasures of Teaching Reform [J].Journal of Hubei Correspondence University, 2008, 12:70

[8] Zhang Pingli. On Inquiry Teaching in track and field courses in physical education institutes [J]. years, 2012, 9:114. 